\title{
DO TEATRO ESCOLAR NO COLÉGIO DAS ARTES DE COIMBRA AO TEATRO DE ANCHIETA
}

Maria Margarida Miranda ${ }^{\mathfrak{1}}$

mmiranda@fl.uc.pt

RESUMO: Após evocar a estada de José de Anchieta como estudante no Colégio das Artes de Coimbra, o presente ensaio descreve algumas das práticas pedagógicas que tomaram lugar ali e que, eventualmente, conformaram suas obras dramatúrgicas. Com referència a isso, a prática do teatro escolar nos cursos de Retórica é posta em relevo, inclusive no Colégio da Guiena, onde a maior parte dos quadros do Colégio das Artes havia servido, no passado, como professores. Dentro desse pano de fundo, algumas reflexões concludentes sobre a especificidade catequética e missionária das obras dramáticas de Anchieta são propostas.

Palavras-chave: Anchieta; Colégio das Artes; Teatro Jesuitico; Retórica; Pedagogia

\section{Anchieta no Colégio das Artes da Universidade de COIMBRA}

A fundaçāo em Coimbra, em 1548, do Colégio das Artes, ou Colégio Real, foi o aspecto mais marcante das reformas de D. Joāo III em matéria de instrução. Destinava-se o Colégio a ensinar as Humanidades a todos os estudantes que quisessem frequentar as Faculdades superiores, para deste modo transformar Coimbra numa Academia digna das aspirações

1 Professora da Faculdade de Letras da Universidade de Coimbra, Portugal 
culturais do Renascimento. A criação dessa original instituição confiava-a o rei ao Mestre André de Gouveia, cuja fama como pedagogo excedia já a de seu tio Diogo na função de Principal do Colégio de Bordéus. Por sua vez, Mestre André trazia consigo de Bordéus os principais regentes seus colaboradores, todos eles homens de grande reputação nas Letras e Humanidades: João da Costa, Diogo de Teive, Nicolau de Grouchy, Guilherme de Guérente, Elias Vinet, Arnaldo Fabricio, Jorge Buchanan, entre outros.

Ora, é precisamente nesse ano que chega a Coimbra o jovem José de Anchieta. Vem com seu irmão, Pedro Nunez, que se matricula na Universidade e dirige-se ao Colégio Real de Coimbra, recentemente fundado - caminho obrigatório para eventualmente seguir mais tarde os passos do irmão. Acompanhava todos os escolares de Humanidades que até aí frequentavam os Gerais da Universidade, e muitos outros que vinham de todo o país, atraídos pela fama de tais mestres. Tenha ou não estado presente na sessão inaugural do Colégio, Anchieta ${ }^{2}$ foi, portanto, um dos primeiros 1.000 discipulos daquele ilustre corpo docente, que veio a merecer do monarca múltiplos louvores ${ }^{3}$

O mesmo não pensavam provavelmente os cónegos regrantes de Santa Cruz, subitamente preteridos nos privilégios reais, e compelidos a entregar alguns dos seus próprios edifícios para a instalaçāo dos novos gerais. Na verdade, o Colégio das Artes ia ocupar provisoriamente uma boa parte da Rua da Sofia, que era propriedade dos Cónegos: o edifício do Colégio de S. Miguel com as casas anexas, e o de Todos-osSantos, que os frades ainda tinham em construção.

\footnotetext{
2 A abertura solene do Colégio das Artes foi em 21 de Fevereiro de 1548, e a noticia mais antiga que temos da presença de Anchieta em Coimbra è de Outubro desse ano.

3 Vıотт S. J., P. Hélio Abranches. Anchieta. Apóstolo do Brasil. São Paulo: Loyola, 1980. 28, n.8 prova que Anchieta foi efectivamente aluno do Colégio das Artes, nomeadamente de Diogo de Teive.
} 
Foi neste lugar que habitou Anchieta. Foi ai que ele se encontrou com o Novo Mundo; foram estes os mestres que despertaram nele as qualidades literárias e humanisticas, patentes nos seus escritos, como oportunamente tem demonstrado o Senhor Doutor Costa Ramalho ${ }^{4}$. Foram estes, portanto, os mestres do apóstolo do Brasil. Lembrou ainda o mesmo autor, que o facto de em 1551 Anchieta se ter feito jesuita não o obrigava a abandonar o Colégio das Artes. Os noviços da Companhia continuavam, na verdade, a frequentar aquele estabelecimento, e por isso, quando o Colégio das Artes foi entregue à Companhia em 1555, o número de jesuitas tinha ai aumentado 5

Como terá sido essa entrada de Anchieta no mundo académico de Coimbra? Quem foi esse estrangeiro entre os da sua classe? Como era a disciplina neste colégio e como se educavam então os alunos para as Letras?

Da escolaridade de Anchieta diz-nos o seu primeiro biógrafo (um ano após a sua morte) que, na cidade de Coimbra, "com a grande habilidade que tinha, cedo se mostrou dos melhores da primeira classe, e juntamente aprendeu a falar português tão propriamente como se mamara essa lingua no leite, cousa que raramente se acha nos que têm a língua castelhana por natural" E mais à frente refere ainda as grandes esperanças que aquele noviço dava à Companhia, "com sua boa índole, muito engenho e felicissima memória" ${ }^{6}$ (Recorde-se que a "primeira classe" a que o autor se refere correspondia no modus parisiensis, à classe mais elevada dos estudos de Latinidade, e nāo à classe de iniciação).

4 Entre outros titulos, "Coimbra no tempo de Anchieta (1548-1551)" $8^{\circ}$ Congresso Brasileiro de Lúngua e Literatura. Ediçōes Geniasa. Rio de Janeiro, 1976. 46-69: "Anchieta em Coimbra" Humanitas. 29-30 (1977-78) 226-229.

5 RAMALHO. A. Costa, Recensāo a Leodegário A. de Azevedo Filho. A Obra de Anchieta e a literatura novilatina em Portıgal. Rio de Janeiro, 19S5. 53 pp., in Humanitas. Coimbra. 37-38 (1985-1986) 382-386.

¿ CAXA. Quiricio. "Breve relação da vida e morte do P. José de Anchieta. $5^{\circ}$ Provincial que foi do Brasil" Brotéria 18 (1934) 169. 
Acompanhemos o dia a dia dos mestres e dos alunos, tal como estabeleciam os estatutos do Principal André de Gouveia (de Abril de 1548), e vejamos em particular o caso dos pensionistas. Às 4h da manhã um porteiro tinha o encargo de percorrer as várias câmaras, acordando os escolares com uma sineta, e dando-lhes luz nos meses de inverno. Uma hora depois começava a oração privada, e às $6 \mathrm{~h}$ a missa, a que todos deviam comparecer. Os nomes dos faltosos eram entregues ao Principal por um elemento de cada classe, para isso designado.

Depois da primeira refeição da manhã, a sineta soava de novo às 7 h30, para que às oito em ponto começasse a primeira aula. Duas horas de praelectio, seguidas de três horas de disputationes, até às 13 horas. No periodo da tarde, as praelectiones eram das 3 às 5 horas, seguidas de uma hora de disputationes. Ceia às 6 horas, finda a qual se reuniam os discipulos com os seus mestres nas salas de aula para as célebres repetições, em que os alunos expunham ao professor, outras vezes a um elemento da classe, o conteúdo das liçōes daquele dia. Depois do canto do hino próprio do tempo litúrgico, o mestre continuava ainda o seu ofício. O repouso doméstico só o conseguia depois de acompanhar o grupo de pensionistas de sua câmara na realização dos múltiplos exercícios diários $^{7}$ E o Principal em pessoa percorria diariamente todas as câmaras para observar a actividade dos alunos. Eis o horário de trabalho de Anchieta e dos seus mestres.

Por essa altura, em Coimbra e em toda a parte, era crescente o interesse pelas Humanidades e pela Retórica. Na nova instituição queria o monarca que se ensinassem Gramática,

7 Vd. "Regimento do Colégio das Artes de 16 de Novembro de 1547" apud FERREIRA, Francisco Leitāo, Noticias Cronológicas da Universidade de Coimbra. Segunda Parte (1548-1551). Coimbra: 1944, 283-308: O mesmo documento pode encontrar-se ainda em BRANDĀO, Mário. Documentos de D. Joāo III. Coimbra, 1939. vol. III, 108-117: TEIXEIRA, José António, Documentos para a história dos Jesuitas em Portugal. Coimbra, 1899, n.40. 
Retórica e Poesia, Lógica, Filosofia, Grego e Hebraico ${ }^{8}$. Se, portanto, os curricula escolares mudavam, tais mudanças traziam consigo uma pedagogia também renovada ${ }^{9} \mathrm{E}$ os humanistas chamados ao Colégio das Artes iam fazê-lo de forma sistemática.

No plano ideológico, os modelos incontestáveis eram agora Cícero e Quintiliano. No plano dos métodos, André de Gouveia e os seus colaboradores (bordaleses e parisienses) não faziam mais do que trazer para o novo ginásio as práticas escolares havia muito experimentadas em todas as instituições escolares de França, a começar pela Universidade: ordem e exercício eram os dois traços distintivos do modus parisiensis ${ }^{10}$

O que caracterizava este sistema pedagógico era, por um lado, distinguir com firme rigor os cursos e as classes de alunos e estabelecer dentro de cada classe diferentes ordens, segundo graus de aprendizagem ${ }^{11}$; por outro lado, chamar o

8 Vd. o mesmo Regimento, apud FERREIRA. Francisco Leitão, Noticias Cronológicas... 283-292.

9 Sobre o lugar da Retórica na pedagogia dos humanistas portugueses e europeus, vd. CASTRO, A. Pinto "La Poétique et la Rhétorique dans la Pédagogie et dans la Littérature de L'humanisme Portugais", L'Humanisme Portugais et l'Europe - Actes du XXI Colloque International d'Études Humanistes. Tours. 313 Juillet 1978. Paris: Gulbenkian, 1984, 699-721. Sobre os principios que presidiam à pedagogia do Humanismo é assinalável o artigo de SOARES. Nair N. Castro, "Pedagogia e Humanismo" Humanitas. 47 (1995) 799-844. Para o caso específico da pedagogia humanistica nos colégios jesuíticos vide MIRANDA. Margarida "Uma paideia humanística: a importāncia dos estudos literários na pedagogia jesuitica do séc. XVI". Humanitas 48 (1996) 223-256.

10 Apesar de ser este o nome que o tornou conhecido, este sistema educativo já fora criado e posto em prátíca pelos Irmãos da Vida Comum Um estudo mais completo sobre o modus parisiensis e a pedagogia dos Jesuitas encontra-se em CODINA MIR, G.. Aux sources de la pedagogie des jésuites. Le modus parisiensis. Roma: Institutum Historicum Societatis lesu. 1968, maxime 151-181 e 99-147.

11 Quando os primeiros jesuitas adoptaram em Itália o modus parisiensis, a seu lado prevalecia ainda um ensino mais solene do que eficaz, a alunos e auditorios de várias capacidades, sem que os professores se apercebessem do aproveitamento dos estudos. Cfr. BARBERA, Mário, La Ratio Studiorum e la parte IV delle Costituzioni della Compagnia di Gesu. Traduzione com introduzione $e$ note. Padova, 1942, 51 . 
aluno a uma actividade múltipla e constante, sempre acompanhado pela vigilância do mestre e estimulado pelos mais variados processos de emulação.

Prova desta pedagogia diferenciada era a divisão do curso de Latinidade em dez classes, entre as quais se devia transitar durante o ano escolar. Deste modo, jamais um aluno estaria em classe inadequada às suas competências, pois o Principal tinha poder para o deslocar em qualquer altura do ano, inclusivamente para uma classe inferior.

Nos programas elaborados por André de Gouveia para o Colégio de Guiena, em Bordéus, e muito provavelmente adoptados em Coimbra, a Retórica de Cícero e de Quintiliano tinha efectivamente um lugar de grande importância. Segundo Mário Brandão ${ }^{12}$, as três classes mais altas já estudavam livros inteiros de cartas de Cícero, bem como alguns discursos, especialmente os que o autor consagrava à Retórica. Esse trabalho era, porém, acompanhado da aplicação prática dos preceitos aprendidos, em constantes exercicios de composição. Finalmente, os alunos da primeira classe estudavam os historiadores, poetas e oradores clássicos em função de todos os preceitos teóricos aprendidos, a fim de saberem compor não só com correcção mas também com elegância e perfeição. E essa perfeiçāo de modo nenhum era indiferente à cultura e à erudição. Por isso, na linha de Cícero e de Quintiliano. a Retórica não era apenas a arte da eloquência mas também o lugar da sapiência.

\section{Algumas práticas pedagógicas: o teatro escolar Na CLASSE RETÓRICA}

Os novos objectivos pedagógicos exigiam do aluno um trabalho essencialmente activo, nāo consagrado ao avanço da ciência em si mesma, mas ao desenvolvimento das fun- 
ções intelectuais do educando, as quais fariam dele simultaneamente um homem de bem e um bom orador, segundo os modernos critérios da Europa do Renascimento.

Na classe de Retórica aperfeiçoavam-se todos os exercícios práticos que permitiam ao aluno possuir as regras da persuasão. O domínio perfeito da palavra passava por uma incansável actividade de exercícios específicos, que iam desde a palavra escrita à palavra declamada. O aluno devia estar habituado a discutir e a mostrar-se em público. O Teatro era, portanto, o ponto mais alto de uma série de mecanismos cénicos didácticos que pretendiam activar todas as energias do educando e colocá-las ao serviço da aprendizagem: repetiçōes diárias diante do mestre, declamaçōes semanais, diante da classe ou, mais solenemente, diante de outras classes e até do Principal do Colégio, e ainda as célebres disputationes ou concertationes. Esta última era uma prática que, baseada no princípio da emulação, consistia em transpor para as classes de Letras o método das disputas típico do ensino das Artes e da Teologia, em que se fazia um debate para discutir determinadas opiniões, submetendo-as à prova da crítica. $\mathrm{O}$ resultado era uma assimilação mais pessoal e convicta dos conteúdos ${ }^{13}$

\section{Teatro escolar: do Colégio de Guiena ao Colégio das Artes e aOs Colégios Jesuíticos}

Do benefício de todos estes exercícios veio a colher o sistema de ensino jesuitico, bem como, aliás, de todos os estimulos ao estudo, que então a vida escolar punha em prática, nomeadamente a celebração de Actos Públicos la renouatio studiorum, por exemplo, ou a festa do santo padroeiro do Colégio). Coincidiam estas datas com a representação

13 Para um desenvolvimento especifico de cada um destes exercicios vd. MIRANDA, M., “Uma paideia humanística..." 239-240: 247-255. 
solene de um drama, normalmente em latim ${ }^{14}$ que absorvia toda a vida do colégio, e que era da responsabilidade do professor de Retórica.

Cabe pois salientar o modo como o fenómeno escolar do teatro jesuítico, que tão amplo papel teve na educação jesuitica em todas as partes do mundo, veio a receber um grande impulso da parte dos professores do Colégio de Guiena e mais tarde do Colégio de Coimbra ${ }^{15}$

Já em 1533, o primeiro Principal do Colégio de Bordéus, Mestre João de Tartas, introduzira o teatro de forma sistemática na vida escolar do Colégio a que presidia: cada professor tinha o dever de compor e pronunciar regularmente discursos, diálogos e comédias. Apesar deste e de outros méritos de Tartas, a confiança que os magistrados tinham no mestre foi, porém, esmorecendo, e no ano seguinte a escolha foi para André de Gouveia, então principal no Colégio de Santa Bárbara e, segundo o testemunho de Montaigne, que conheceu pessoalmente as suas funções em Guiena, o maior principal de França. Ora, foi precisamente no tempo de André de Gouveia que o teatro escolar conheceu o seu maior esplendor, com a obra de Jorge Buchanan.

Entre 1539 e 1542, Buchanan apresenta em Bordéus duas adaptações latinas de Euripides (Medeia e Alceste) e dois outros dramas de inspiração bíblica: Baptista ou Calúnia e Jephte, ou $O$ Voto $^{16}$

Outros professores fizeram também representar as suas tragédias latinas, como Guilherme Guérente e Marco António Muret. Comédias, tragédias e diálogos tornaram-se os exercí-

14 O Latim era a única lingua admitida no regulamento destes colégios. e havia uma severa disciplina para manter esta regra.

15 Um estudo comparativo dos dois colégios congéneres e das suas raizes comuns pode ver-se em CODINA. MIR. Aux sources de la pedagogie des jésuites... 192-218.

is SHARRAT. R. e WALSH. P. G. (ed), George Buchanam Tragedies. Scotish Academic Press. 1983. 
cios literários mais apreciados pelos escolares e pela cidade inteira, que vinha assistir às representações e aplaudir os seus filhos.

Guando estes mestres vieram para o Colégio Real de Coimbra, nele instalaram os mesmos hábitos: solenes Actos Públicos, em que os alunos apresentavam diante da cidade os progressos alcançados nos seus estudos, com as suas próprias composições, em prosa ou em verso, ou com a apresentação de uma peça de teatro.

Convém todavia salientar que não foram os mestres bordaleses que introduziram o teatro no meio universitário de Coimbra. Em Coimbra eles encontraram, aliás, uma sólida tradição dramática escolar (anterior pelo menos a 1538) ${ }^{17}$ Antes da fundação do Colégio, os professores da terceira e quarta classe de latim da Universidade eram obrigados a compor e a apresentar anualmente uma comédia - no momento e no lugar designados pelo Reitor ${ }^{18}$. Ora, a abertura do Colégio das Artes não podia deixar de dar um novo vigor a esta tradição coimbrã, pois com André de Gouveia vinham os melhores dramaturgos, como Buchanan, Guérente e Diogo de Teive, que tinham distinguido o Colégio de Guiena, entre as outras instituições escolares de França, pelo cultivo do teatro escolar.

Ainda que a documentação desta época não dê notícias certas sobre representaçōes dramáticas no Colégio das Artes, podemos admitir com certa probabilidade que os mestres de

17 É desta data um alvará de D. Joāo III que levantava aos estudantes a proibiçāo de usarem, nas suas representaçōes, vestes de seda. desde que tais vestes tivessem sido fabricadas antes da dita proibição (BRANDĀO, M., Documentos de D. Joāo III. vol. I, 75. e vol. III, 47).

180 subsidio, de 15 cruzados, oferecido pelo monarca evidencia o interesse programático por este género de representaçōes, tendo em vista a reforma dos estudos. Sobre o teatro escolar em Coimbra e em Portugal vd BRANDĀO. Mário. A Inquisiçāo e os professores do Colégio das Artes. Coimbra, 1969, vol. II, 996-1010: FRĖCHES. Claude-Henri. Le Theâtre Neo-latin au Portugal (15501745). Paris-Lisbonne: Nizet-Bertrand. 1964. 
Retórica tenham feito representar as peças que já tinham composto. E aquelas que não chegaram a ser representadas eram pelo menos conhecidas em manuscrito, senão em livro - a Medea, de Buchanan, por exemplo, já tinha vindo à estampa, em 1544.

O mesmo aconteceria com as obras de Diogo de Teive. Deste humanista sabemos que compôs duas peças de tema biblico, hoje perdidas: Judith e David. Pelo menos esta última, cujos Coros musicais ainda eram célebres, meio século depois, foi representada em Coimbra, em 1550, no mosteiro da Santa Cruz, por jovens alunos do Colégio Real. A única peça de Teive que chegou até nós foi a que compôs, em 1554 , sobre a morte do Principe D. João - uma tragédia latina em moldes clássicos destinada certamente a ser representada no Colégio das Artes, mas que nunca seria posta em cena (apenas foi publicada em 1558$)^{19}$.

Da actividade dramática de Coimbra ao tempo de Anchieta há ainda notícia de uma comédia de Plauto ter sido representada, para celebrar uma visita de D. João III ao colégio, em $1550^{20}$

Depois que D. João III entregou o Colégio à Companhia de Jesus, diálogos, comédias e tragédias sucedem-se com a regularidade de quaisquer exercicios ou Actos Públicos. Alguns dos seus autores iam ganhar fama internacional, e as suas peças iam espalhar-se por toda a Europa em cópias manuscritas ou impressas, para conhecerem uma longa história de representações ${ }^{21}$ A aura que rodeava os antecessores

19 SOARES, Nair de Nazaré Castro, Tragédia do Príncipe Joāo, introduçāo, texto, versāo e notas. Coimbra. 1999 (ediçāo revista e actualizada).

20 FRECHES, Claude-Hemi, Le Theâtre Neo- latin... 240 ss. Estas eram as representaçōes oficiais, com apoio das instituiçōes e dos mestres. Mas havia também representaçōes de estudantes, de carácter mais popular, em lingua portuguesa, celebranclo certos actos académicos ou acontecimentos festivos. Cada doutorando. por exemplo. tinha de celebrar a obtençāo do grau, levando à cena uma comédia (Cfr. BRANDĀO, Mário, A Inquisiçāo... vol. II, 1007-1009).

21 Foi o caso do P Miguel Venegas e do P. Luis da Cruz. 
dos jesuítas em Coimbra, e particularmente o prestígio da sua produção literária, não pode ter sido alheia ao investimento que os jesuitas punham agora em grandiosos Actos Públicos, como a distribuição de prémios literários ao alunos, acompanhadas de solenes representações teatrais. Com efeito, outros Colégios contemporâneos não o faziam ainda com o mesmo esplendor, nem de forma tão sistemática.

Ora, é neste momento que passa pelo Colégio de Coimbra uma geração de homens que irá marcar profundamente o modo de ensino e os programas de estudos de todos os Colégios da Companhia: os retóricos Cipriano Soares e Miguel Venegas, o humanista Pedro Perpinhão, o filósofo Pedro da Fonseca, o gramático Manuel Álvares.

A Pedro Perpinhāo, por exemplo, em 1565, três anos depois de ter deixado Coimbra, pedia-se que desse alguns elementos sobre o ensino no Colégio Real, no tempo em que aí leccionara. O resultado foi o De ratione liberorum instituendorum litteris latinis et graecis ${ }^{22}$ Pedro Perpinhão não pertenceu a nenhuma das comissões encarregadas da elaboração da Ratio Studiorum mas este opúsculo não pode ter deixado de assistir aos seus últimos redactores, pois são numerosos os pontos de contacto. A parte final do seu tratado incidia sobre as vantagens pedagógicas dos estímulos ao estudo, particularmente da distribuição de prémios e da realização de exercícios públicos. De facto, é Pedro Perpinhão quem encontramos no júri da primeira sessão pública deste género de celebrações - no Colégio Real de Coimbra, em 1557 - e é o mesmo que vemos, sete anos depois (em 1564), inaugurar a mesma prática no Colégio Romano, aquele que serviria de modelo para todos os Colégios.

Concursos e prémios literários, e públicas representaçōes dramáticas vieram assim a tomar-se ocasião das maio-

22 Vd. Monumenta Historica Societatis lesu, Monumenta Paedagogica S.l..vol. I-IV, Roma: Institutum Historicum S.I., 1965-1981, II, 644-657. Um comentário a este tratado pode ver-se em MIRANDA, M., “Uma Paideia humanistica..” 233-234. 
res solenidades do ano académico, não apenas como exercício escolar mas como verdadeira intervenção na vida cultural contemporânea. Mais do que recreio, estas representações eram um exercicio do ensino da Retórica e das Humanidades mas tarnbém uma forma de identificar afectivamente os pequenos actores com os bons costumes de personagens sempre edificantes ${ }^{23}$. Por isso o teatro se tornou objecto obrigatório da regulamentação da Ratio Studiorum ${ }^{24}$, para finalmente se impor aos Colégios de todo o mundo.

\section{Teatro Jesuítico e Teatro de Anchieta}

Aparentemente já nos teremos desviado de Anchieta, das suas trovas ao gosto popular, dos seus Autos em português, tupi, espanhol, por vezes em latim macarrónico... Com efeito, todas as representações de colégio, mesmo nos colégios do Brasil, deviam ser necessariamente em latim, por serem cousas mais escolásticas e graves - assim insistia o $\mathrm{P}$ Geral, perante o pedido do $\mathrm{P}$ Visitador, Cristóvão de Gouveia, para que o português fosse permitido, em nome do entendimento. Os jesuitas brasileiros tiveram de facto algumas dificuldades ern adaptar-se aos costumes europeus da Companhia. Mais facilmente se adaptavam ao gosto indigena pelas representações, pelas danças e pelo canto, acompanhadas de instrumentos primitivos. Trocando apenas as letras, os padres aproveitavam as disposições inatas dos índios e levavam-nos, pouco a pouco e sem violências, à prática dos bons costumes e da religião. Isso mesmo levantou as críticas do primeiro Bis-

23 Sobre os objectivos didácticos e pedagógicos deste teatro no ensino da Retórica e dos bons costumes, vd. MIRANDA. M., "Uma paideia humanistica..." maxime 247-250, bem como "Teatro Jesuitico: Miguel Venegas. Dramaturgo e Mestre de Retórica" in. FERREIRA, José Ribeiro (ed.), A Retórica Greco- Latina e a sua perenidade. Porto. 2000. vol.II, pp. 656-669, ou ainda, de forma mais sistemática. Teatro nos Colégios dos Jesuitas. Lisboa, Fundaçāo Calouste Gulbenkian, 2006. são portuguesa de Margarida MIRANDA. Lisboa: Esfera do Caos, 2009. 
po do Brasil, D. Pedro Fernandes Sardinha, que se indignou com tantas concessōes aos costumes gentílicos, e se apressou a escrever para Portugal: Além de serem provocadores do mal são tão dissonantes da razão que não sei quais são as orelhas que podem ouvir tais sons e rústico tocar. E aos domingos, acrescentava o prelado, os padres tinham cantares a Nossa Senhora ao tom gentílico, e tocavam os mesmos instrumentos que aqueles bárbaros usavam quando queriam beber seus vinhos e matar seus inimigos ${ }^{25 !}$

As mesmas concessōes fazia José de Anchieta nos seus autos sacros, quando a aldeia recebia solenemente relíquias de santos, ou quando recebia a visita do Provincial. Os seus objectivos eram tão didácticos como os do teatro de Colégio, mas menos escolásticos. Não se tratava de fazer propaganda teológica, mas de ensinar costumes. O teatro de Anchieta era dirigido não só a colonos, soldados, marinheiros, e negociantes, mas sobretudo aos indios silvicolas, a quem era preciso, antes de mais, dar uma lei que os afastasse da antropofagia e da poligamia. As cartas dos Padres são unânimes em afirmar a superioridade do seu talento. Mas - é o próprio Anchieta quem se queixa - por ser esta terra relaxada, remissa e melancólica, tudo se vai em festas, cantar e folgar ${ }^{26}$ Esta era uma das dificuldades com que mais frequentemente se debatiam os primeiros educadores do Brasil: o escasso interesse local pelos estudos. Além disso, se nos colégios ao modo europeu havia lugar para a função temivel do Corrector, a verdade é que aos meninos indios não se podia ralhar, muito menos castigar. Os indios, na verdade, fugiam para o mato com os mais fúteis pretextos: bastava que se lhes falasse mais alto, ou se lhes castigasse um filho.

25 Carta de D. Pedro Fernandes Sardinha ao P. Simāo Rodrigues, de Salvador, a 6 de Outubro de 1553, apud LEITE. Serafim. História da Companhia de Jesus no Brasil. Livraria Portugália, 1938, Tomo II, pp. 105-107

${ }^{26}$ Anchieta. Cartas. 415, apud LEITE, Serafim, História da Companhia de Jesus no Brasil. Tomo I, 83. 
O teatro foram os colonos que o trouxeram para o Brasil - nas igrejas representavam-se autos à moda portuguesa. Os escritos contemporâneos sublinham o gosto dos indigenas por qualquer género de representações ${ }^{27}$

O jogo cénico e dramático, as personagens alegóricas, a dança, a música, o colorido das vestes eram as linguagens que encontravam a maior simpatia dos indios, e que permitiram a Anchieta criar um teatro que se tornou um "catecismo em imagens" especificamente adequado ao povo que queria converter ${ }^{28}$.

O que há, entāo, de comum entre os Autos populares de Anchieta e o teatro humanístico dos Colégios? Que semelhanças pode haver entre o erudito teatro jesuítico do continente europeu e o teatro em linguas indigenas, nas aldeias dos indios?

Com esta questão abre-se um imenso campo de investigação nas literaturas comparadas e na história do teatro nas diversas missōes jesuíticas. O que as consideraçōes acima feitas permitem afirmar é que, se José de Anchieta foi o fundador do teatro brasileiro, foi-o sem dúvida com as propícias circunstâncias que nesta terra encontrou. Mas a semente, essa veio consigo de Coimbra - a mesma semente, aliás, que havia de frutificar na legislação positiva da Ratio Studiorum sobre teatro escolar, nos Colégios de todo mundo.

Quando Anchieta deixou Coimbra e fez nascer o primeiro núcleo de civilização nos sertões de Piratininga, trazia consigo a ideia de que o teatro era um precioso auxílio pedagógico e um excelente instrumento missionário.

27 "Memorial" do P. Beliarte, ibidem 599-613.

28 A expressão é de FRECHES. Claude-Henri, no comentário que faz à obra dramática de Anchieta: "Le Théâtre du P. Anchieta. Contenu et structures" Napoli, Annali dell'Istituto Universitário Orientale Sezione Romanza (1961) 47-70. 